\title{
Comparison of knowledge, attitudes and practices on exclusive breastfeeding between primiparous and multiparous mothers attending Wajir District hospital, Wajir County, Kenya: a cross-sectional analytical study
}

\author{
Mahat Jimale Mohamed ${ }^{1 *}$, Sophie Ochola ${ }^{1}$ and Victor O. Owino ${ }^{2}$
}

\begin{abstract}
Background: Exclusive breastfeeding (EBF) is recommended for 6 months of age, with continued breastfeeding for 2 years of age or beyond. There is paucity of information on the disparity in Knowledge, Attitudes and Practices (KAP) on EBF between primiparous and multiparous mothers. This study compared the KAP on EBF between primiparous and multiparous mothers attending Wajir County Hospital, Wajir County, Kenya and investigated the association between maternal knowledge and attitudes and EBF.

Methods: Information on maternal KAP on EBF was collected through structured researcher administered questionnaires for a total of 281 mothers, recruited from a maternal and child health centre in 2014; primiparous $(n=137)$ and multiparous $(n=144)$ with infants $0-5$ months of age. Maternal knowledge and attitudes on various aspects of breastfeeding were determined. The knowledge and attitude scores were also calculated. The practice of EBF was determined based on a 24-h recall.

Results: The prevalence of EBF among infants $0-5$ months old was $45.5 \%$. The rate of EBF among primiparous mothers was $39.4 \%$ and multiparous mothers $49.3 \%$. The knowledge score on breastfeeding (out of a total of 10) for the primiparous mothers was $7.93 \pm 2.10$ and $7.49 \pm 2.20$ for the multiparous mothers. The mean attitude score (out of a total score of 40 ) for the primiparous mothers was $29.46 \pm 5.65$ and $28.65 \pm 6.40$ for the multiparous mothers. The prevalence of EBF and maternal knowledge and attitudes towards breastfeeding was similar among the two groups of mothers. Those mothers with positive attitudes towards breastfeeding were more likely to EBF (Fisher's exact test; $p=0.00$ ) compared with those with lower scores.

Conclusions: Interventions to promote exclusive breastfeeding should be tailored to the needs of each population by identifying the factors that influence the practice in a given context. The findings of this study will be useful particularly for behavior change communication interventions by those organizations working in similar circumstances to the study area.
\end{abstract}

Keywords: Knowledge, Attitude and practices (KAP), Primiparous mothers, Multiparous mothers, Exclusive breastfeeding, Kenya

\footnotetext{
* Correspondence: majimo114@gmail.com

1 Department of Food, Nutrition and Dietetics, Kenyatta University, P.O BOX

438433, Nairobi 00100, Kenya

Full list of author information is available at the end of the article
} 


\section{Background}

The WHO and UNICEF recommend exclusive breastfeeding (EBF) for the first 6 months of life [1]. Exclusive breastfeeding is defined as giving no other food or drink to the infant, not even water, except breast milk (including milk expressed or from a wet nurse) for the first 6 months of life, but allows the infant to receive ORS (oral replacement solution), drops and syrups (vitamins, minerals and medicines) [2]. The World Health Assembly (WHA) has set a global target to increase the rate of exclusive breastfeeding globally to $50 \%$ by 2025 [3]. Exclusive breastfeeding is regarded as one of the most powerful tools policy-makers have at their disposal to improve the health of their population and economies [4].

Globally, only $38 \%$ of infants are exclusively breastfed [5]. In East Africa, the EBF rates are quite impressive with Rwanda (84.9\%), Burundi (69.3\%), Uganda (63.2\%), Kenya (61.4\%) and Tanzania (50\%) all having more than half of the infants 0-5 months old exclusively breastfed [5]. Despite the recent increase in EBF to $61.4 \%$ [6] from 32\% [7], Kenya has the second lowest rate among the East African countries. Exclusive breastfeeding rates in Wajir County Kenya, the study site is $43.6 \%$ which is way below the national rate and the WHO target of $90 \%$ [8].

In Kenya, the Ministry of Health targets an annual increase of $3 \%$ for the country translating to a rate of $56 \%$ by the years 2016/2017 [9]. The Kenya National Nutrition Action Plan 2012-2017 has mainstreamed promotion of exclusive breastfeeding as one of the priority nutrition interventions in the country [9]. Currently, Infant and Young Child Feeding (IYCF) counselling is conducted at government health facilities during growth monitoring and promotion of children less than 5 years of age to mothers and/or caregivers of children already at risk of malnutrition. Counselling on IYCF has also been included in the roles of Community Health Volunteers (CHVs) under the umbrella of the "Community Health Strategy". Other community based initiatives include the Baby Friendly Community Initiative and Mother-to-Mother Support groups [9].

Primigravidas are regarded as a vulnerable group in which insufficient messages may lead to decreased chances to achieve EBF [10]. Primigravidas are more accepting of non-scientific health promotion messages received through various sources [11]. Primiparous mothers, compared to multiparous mothers, have been observed to have more challenges in practicing EBF being their first experience. Primiparous mothers are less likely to practice exclusive breastfeeding through to 6 months and less likely to breastfeed for 2 years and more [12]. They may have difficulties in adjusting to the new role and less breastfeeding skills [13]. Among the primiparous mothers, factors shown to influence or predict EBF are breastfeeding self-efficacy, breastfeeding outcome expectancy, sociocultural factors and early initiation of breastfeeding [14].
Many studies have demonstrated that multiparity is associated with longer exclusive breastfeeding [15-19]. Studies have shown that breastfeeding duration increases with increasing parity and this may be because of previous breastfeeding experiences [20-22]. In contrast, some studies have shown that parity has no significant influence on duration of breastfeeding [23].

No studies have been conducted in Kenya comparing the Knowledge, Attitudes and Practice (KAP) of EBF among primiparous and multiparous mothers. This study therefore compared the KAP on exclusive breastfeeding between these two groups of mothers and investigated the association between maternal knowledge and attitudes and the practice of EBF.

\section{Methods}

Study design

A cross-sectional comparative study [24] was adopted for this study with one group composed of primiparous and the second group of multiparous mothers with infants 0 5 months old.

\section{Terms used in the study were defined as follows}

Prelacteal feed was defined as any food except mother's breast milk given to a newborn before breastfeeding is initiated [25] and post lacteal feed as any food except mother's breast milk given to a newborn after the initiation of breastfeeding [25]. Predominant breastfeeding was defined as breastfeeding a child, but also giving small amounts of water or water-based drinks. Neither food-based fluids, nor solid food, nor non-human milk is allowed under this definition) [26].

\section{Study setting and study participants}

The study was carried out at the Maternal and Child Health $(\mathrm{MCH})$ Clinic at Wajir County Hospital, Kenya. Wajir County is in North Eastern Kenya and is mainly inhabited by the Kenyan Somalis who have common cultural practices. The main livelihood activity among the Somalis is pastoralism. Wajir County has a poverty rate of $84.0 \%$, almost double the national rate of $47 \%$. Wajir is ranked the 45th poorest county out of 47 counties in Kenya. Wajir is one of the counties with the highest burden of malnutrition among the under-fives in Kenya with over $26 \%$ of the children having stunted growth, $14 \%$ wasted and $21 \%$ underweight [6].

The study participants were mothers of infants 05 months old attending the $\mathrm{MCH}$ Clinic at Wajir County Hospital Kenya, during the study period. The exclusion criteria were; mothers with medical conditions or those on medications in which breastfeeding is contraindicated; mothers of infants diagnosed with serious congenital malformations in which breastfeeding was deemed not feasible or contraindicated. These conditions were verified 
from maternal and child health cards and by the clinicians at the hospital. Mothers were recruited into the study upon informed consent.

\section{Study variables}

The dependent variable in this study was the prevalence of exclusive breastfeeding practice among primiparous and multiparous mothers of infants $0-5$ months of age determined by 24-h maternal recall.

The independent variables for the study were maternal knowledge and attitudes towards EBF. Maternal knowledge was tested by 10 questions covering various aspects of breastfeeding. Maternal knowledge score was computed as follows; a correct response was scored one (1) and incorrect responses scored zero (0). The total possible score was 10 . Those mothers who scored less than 3 out of 10 were categorized as having poor knowledge, those who scored 3-6 were considered as having moderate knowledge and those who scored 7 and above were categorized as having high knowledge [27].

Maternal attitudes towards EBF was determined by responses to 10 questions. The Likert Scale was used to rate the maternal attitudes and an attitude score calculated. Each correct (positive attitude) response was awarded a score of 4 whereas an incorrect (negative attitude) response got a score of zero (0). To determine the maternal attitudes towards breastfeeding issues, the strongly disagree (SD) and disagree (D) categories were collapsed into one response category (disagree) while strongly agree (SA) and agree (A) into another (agree). The neither agree nor disagree responses were analyzed as a separate category neutral $(\mathrm{N})$. The total possible score for correct responses for all aspects of attitudes tested was 40 . The higher the maternal attitude score the more positive the attitude towards breastfeeding. Those mothers who scored less than 20 were categorized as having poor attitudes, those who scored 20-30 had moderate attitudes and those scoring 31-40 as had positive attitudes [27].

\section{Sample size determination and sampling procedure}

The calculated sample size was 280 mothers; 140 primiparous mothers and 140 multiparous mothers. The sample size was calculated using the formula by Cochran $[28,29]$. The proportion of the target population estimated to be exclusively breastfeeding nationally was $32 \%$ based on the most recent national rate at the time of the study [7].

The sample size was calculated using the formula by Cochran [30] as follows:

$$
\mathrm{n}=\frac{\mathrm{Z}^{2} \mathrm{pq}}{\mathrm{e}^{2}}
$$

Where $\mathrm{n}=$ the required sample size, $\mathrm{Z}=$ the standard normal deviate at 95\% confidence level (1.96), $p=$ the estimated proportion of the target population estimated to practice EBF (32\%) national rate at the time of the study) [7], q = 1-p; and $\mathrm{e}=$ desired level of precision (0.05) and a non-response rate of $10 \%$. This yielded a sample size of 334 .

Finite population correction was conducted to produce a sample size proportional to the population (a population size less than 10,0000) using the following formula:

$$
\mathrm{n}=\frac{\text { no }}{1+\frac{(\text { no }-1)}{\mathrm{N}}}
$$

Where $\mathrm{n}=$ the sample size; no = desired sample size and $\mathrm{N}=$ the estimate of the population size $(10,000)$.

This yielded a sample size of 250 (125 per group) which was inflated by a non-response rate of $10 \%$ to yield a sample size of 140 .

\section{Sampling techniques and procedure}

A systematic random sampling procedure was used for the study. The average number of mothers with infants $0-$ 5 months of age that visited the $\mathrm{MCH}$ clinic daily at Wajir district hospital was thirty (30), as reported by the health staff at the $\mathrm{MCH}$ clinic. The sampling interval was determined by dividing the average number of mothers (30) that visited the clinic daily with the ideal number of mothers that could be interviewed per day. During the pretest, it was established that the research team (composed of four persons; 3 enumerators and the researcher) could conduct a maximum of 12 interviews per day. The sampling interval was therefore calculated by dividing 30 by 12 to get a sampling interval of 2 . On a daily basis, the first mother to be interviewed was selected by simple random sampling technique using a Table of Random Numbers to select a number between 1 and the sampling interval of 2 . The randomly selected number (either 1 or 2) represented the first mother to be sampled. The next respondent was selected by adding the sampling interval to the number selected. This procedure was used to select the rest of the mothers to be interviewed during that day. The mothers were sampled from the queue as they waited for health services. The same procedure was conducted on the subsequent days until the required sample size was attained, over a 5-week period. The same sampling procedure was used to select primiparous and multiparous mothers. If the selected mother was not eligible for the study, then the next mother on the queue was selected and the sampling interval maintained.

\section{Data collection tools}

A researcher-administered structured questionnaire with both closed and open ended questions were used to collect data. The questionnaire solicited data on: maternal demographic and socioeconomic characteristics; maternal knowledge, attitudes and practices on breastfeeding; sources of 
breastfeeding information; and infant feeding practices. Information on breastfeeding practices included; timing of initiation of breastfeeding, feeding on colostrum, giving of prelacteal and post lacteal feeds and exclusive breastfeeding.

The questions were adopted from a face-content validated questionnaire used in Kenya [31] and customized for this study. The questionnaire was developed in English and translated into Somali the local language and then back translated to English to check for consistently and accuracy. The final draft of the Somali language questionnaire was used for data collection.

\section{Pretesting of data collection tools}

The questionnaire was pretested for clarity, validity and reliability at Wajir County Hospital on a sample size of 28 participants (slightly over $10 \%$ of the study sample size) after which the necessary adjustments and modifications were made to the tool before being used for the actual study. The participants for the pretest did not participate in the actual study. For reliability, the questionnaire was administered to six mothers who met the inclusion criteria and readministered to the same mothers after a week to determine the consistency of the responses. The calculated reliability coefficient was 0.85 . This was within the acceptable range of $\geq 0.7(p<0.05)$ [30]. Content validity was assessed by nutrition experts.

\section{Data collection procedure and techniques}

The researcher and research assistants administered the questionnaire to the sampled mothers in a one-time face to face interview with each study participant at the $\mathrm{MCH}$ clinic at the hospital. The interviews were conducted in a private and quiet room at the $\mathrm{MCH}$, Wajir County Hospital. The data collection took place from June to July 2014.

Informed written or thumb print consent was sought from the respondents who were selected to take part in the study. For mothers who were less than 18 years of age assent forms were signed by the parents or guardians before being recruited into the study. Participants were assured of confidentiality.

\section{Data quality control}

Three enumerators (data collectors) with a minimum of a Diploma in Health or Nutrition qualification were recruited from those residing in the study area, and who speak Somali (the local language) and Kiswahili (the national language) fluently. The enumerators also had previous experience in survey data collection. The enumerators underwent a 2 day training to cover the following: explanation of the study objectives, interview techniques, recording of responses and research ethics.

\section{Data analysis and presentation}

The data was checked, cleaned and coded and analyzed using Statistical Package for Social Sciences (SPSS) version 17.0. Descriptive statistics (frequencies, percentages, means and standard deviation) were used to describe maternal demographic and socioeconomic characteristics, prevalence of EBF, knowledge, attitudes and practice of EBF. A t-test was used to establish for significant differences if any, between the primiparous and multiparous mothers for continuous data. Fisher's exact test was used to test for association between the practice of EBF and categorical variables. A $p$ - value of $<0.05$ was used as the criterion for statistical significance.

\section{Results \\ Infant feeding practices \\ Demographic characteristics of mothers and children}

There was no difference in the age of infants of the primiparous and multiparous mothers (Table 1). The majority of the mothers in the two groups were married. The level of education was low with $43.1 \%$ of the mothers having no formal education (Table 1).

\section{Early infant feeding practices}

The majority of the primiparous and multiparous mothers initiated breastfeeding within the first hour after delivery. A higher percentage $(53.8 \%)$ of multiparous mothers gave prelacteal feeds to their infants compared to primiparous mothers (46.2\%). There were no differences in the early infant feeding practices between primiparous and multiparous mothers (Table 2).

\section{Breastfeeding practices since birth}

The majority of mothers both primiparous and multiparous, reported to have ever breastfed their infants (Fig. 1). Similarly, the majority of the primiparous and multiparous mothers were continuing to breastfeed their infants at the time of the study. Overall, the EBF rate for infants 0-5 months old was $45.5 \%$. The rates of EBF of the primiparous and multiparous mothers were similar, showing no relationship between parity and exclusive breastfeeding rate in this study population.

\section{Maternal knowledge on exclusive breastfeeding}

The majority of the primiparous and multiparous mothers knew that breast milk should be baby's first feed. Most of the mothers also knew that the baby should be put to the breast within the first hour of birth. The knowledge on breastfeeding among the primiparous and multiparous mothers was similar. The mean knowledge score out of a total of 10 was $7.93 \pm$ 2.10 and $7.49 \pm 2.20$ for the primiparous and multiparous mothers respectively. 
Table 1 Infant and maternal sociodemographic characteristics

\begin{tabular}{|c|c|c|c|c|c|c|c|}
\hline & Primiparous & & Multiparous & & Total & & Chi-square test/t-test \\
\hline & $n=137$ & & $n=144$ & & $n=281$ & & \\
\hline & $n$ & $\%$ & $n$ & $\%$ & $n$ & $\%$ & $p$-value \\
\hline Sex of children: & & & & & & & \\
\hline Male & 74 & 54 & 63 & 43.8 & 137 & 48.8 & 0.11 \\
\hline Female & 63 & 46 & 81 & 56.3 & 144 & 51.2 & \\
\hline Age of infant in months (mean \pm ): & $2.8( \pm 1.4)$ & & $2.6( \pm 1.4)$ & & $2.7( \pm 1.4)$ & & 0.23 \\
\hline Maternal age in years: (mean \pm ): & $25.1( \pm 5.3)$ & & $27.4( \pm 5.3)$ & & $26.2( \pm 5.4)$ & & 0.00 \\
\hline Marital Status: & & & & & & & \\
\hline Married & 116 & 84.7 & 118 & 81.9 & 234 & 83.3 & 0.08 \\
\hline Single & 8 & 5.8 & 6 & 4.2 & 14 & 5.0 & \\
\hline Divorced & 5 & 3.7 & 5 & 3.5 & 10 & 3.6 & \\
\hline Separated & 4 & 2.9 & 13 & 9.0 & 17 & 6.0 & \\
\hline Widow & 4 & 2.9 & 2 & 1.4 & 6 & 2.1 & \\
\hline Education: & & & & & & & \\
\hline No formal education & 57 & 41.6 & 64 & 44.4 & 121 & 43.1 & 0.50 \\
\hline Adult education & 8 & 5.8 & 9 & 6.3 & 17 & 6.1 & \\
\hline Primary education & 27 & 19.7 & 32 & 22.2 & 59 & 21.0 & \\
\hline Secondary school & 14 & 10.2 & 15 & 10.4 & 29 & 10.3 & \\
\hline Certificate level & 2 & 1.6 & 5 & 3.5 & 7 & 2.5 & \\
\hline Diploma level & 21 & 15.3 & 15 & 10.4 & 36 & 12.8 & \\
\hline Degree level & 8 & 5.8 & 4 & 2.0 & 12 & 4.3 & \\
\hline
\end{tabular}

The level of knowledge on various aspects of breastfeeding was high. The lowest level of knowledge was observed on the aspect that touched on whether pregnant mothers should continue breastfeeding their infants or not (Table 3).

\section{Maternal attitudes towards exclusive breastfeeding}

The majority of the mothers believed that EBF is beneficial to the child, with no difference between the primiparous and multiparous mothers. Similarly, a good proportion of the mothers believed that breastfed babies are healthier than non-breastfed babies and also that breastmilk is more easily digested than animal milk (Table 4). In contrast, negative maternal attitudes towards breastfeeding were also observed among the mothers. A relatively high percentage of mothers believed that infant formula is a better choice for working mothers, implying a negative attitude towards these aspects of breastfeeding (Table 4). There were no differences in maternal attitudes on the various aspects of breastfeeding between the primiparous and multiparous mothers.

The association between maternal knowledge and maternal attitudes and the practice of exclusive breastfeeding

For the purpose of testing the association between maternal knowledge and attitudes and the practice of exclusive breastfeeding, all those mothers who practiced EBF were pooled together in analysis irrespective of their parity. Similarly, all the mothers who did not practice EBF were pooled together irrespective of their parity. Maternal knowledge was not associated with the practice of EBF (Table 5). Mothers with a positive attitude towards breastfeeding were more likely to exclusively breastfeed their babies than those with negative attitudes $(p=0.00)$ as shown in Table 5.

\section{Discussion}

Several studies have investigated parity as a predictor of the practice of exclusive breastfeeding [16-21] but to the best of our knowledge our study was the first study in Kenya to compare maternal KAP on EBF between primiparous and multiparous mothers.

In our study, exclusive breastfeeding was measured in the previous $24 \mathrm{~h}$ and therefore the true EBF rate since birth would be lower. The study also found no association between EBF and parity.

There is scarcity of information on studies conducted to establish the prevalence of EBF in different areas of Kenya. The findings on the EBF rate in our study are similar to that of a study conducted in the same study area (Wajir County) in 2014 by Islamic Relief Kenya [8] using the same definition of EBF as used in our study. Some studies 
Table 2 Early infant feeding practices

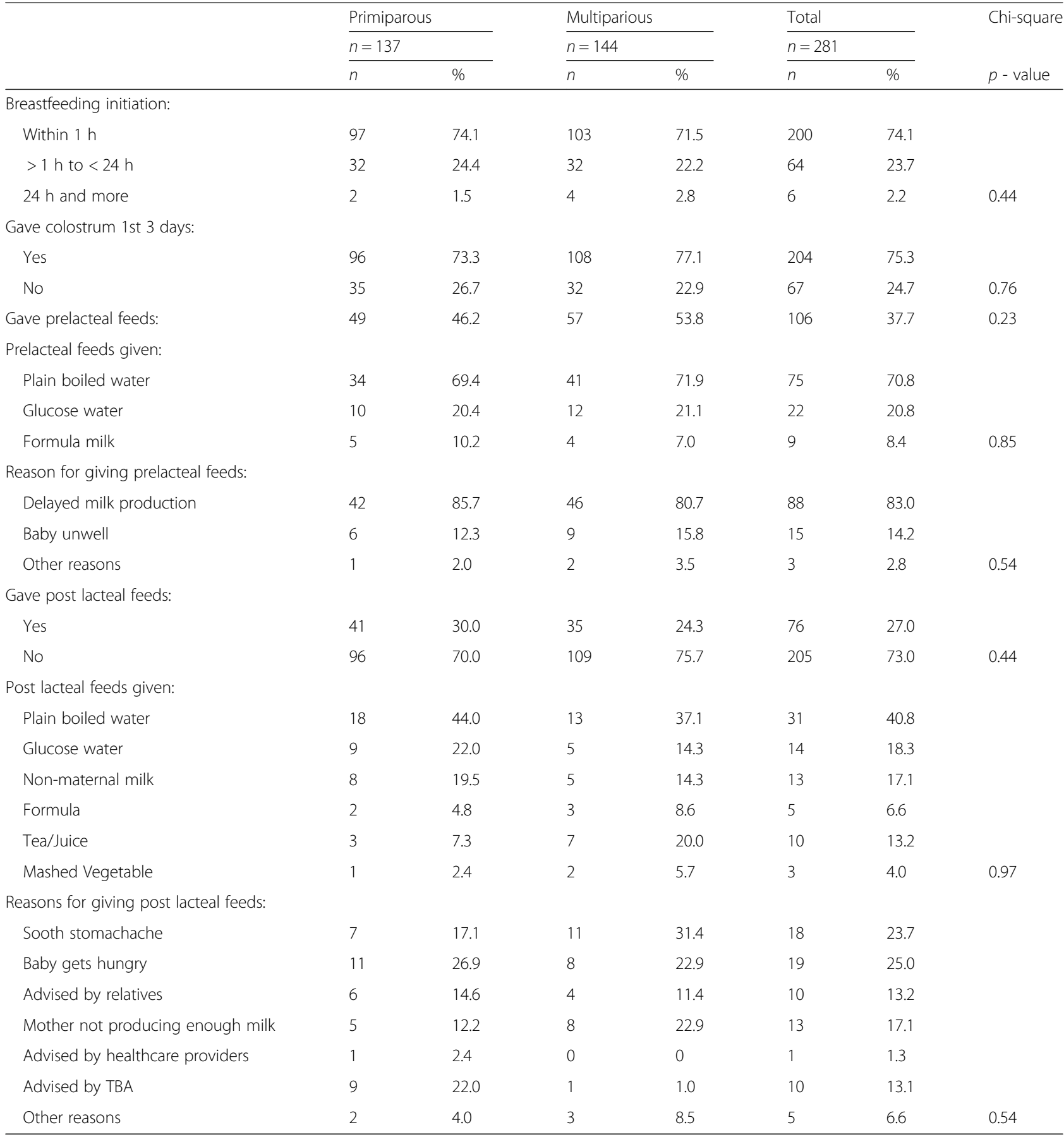

TBA Traditional Birth Attendants

conducted in Kenya, using the same definition of EBF, have however, reported lower rates than reported in our study. A study conducted in Nyando district Kisumu, Kenya reported an EBF rate of 33\% [32]. In another study conducted in the informal settlement in Nairobi, an EBF rate of $2 \%$ was observed [33]. The findings of an intervention study conducted in an informal settlement in Nairobi reported an EBF rate of only 15.6\% after the provision of seven intensive home based counseling sessions [34]. The relatively high rate of EBF reported in our study could be attributed partly to the large presence of NonGovernmental Organizations (NGOs) in the area that are implementing programmes aimed at improving child survival. The NGOs in Kenya work mainly in the Arid and Semi-Arid Lands (ASAL) areas where there is higher vulnerability for malnutrition among mothers and children, 


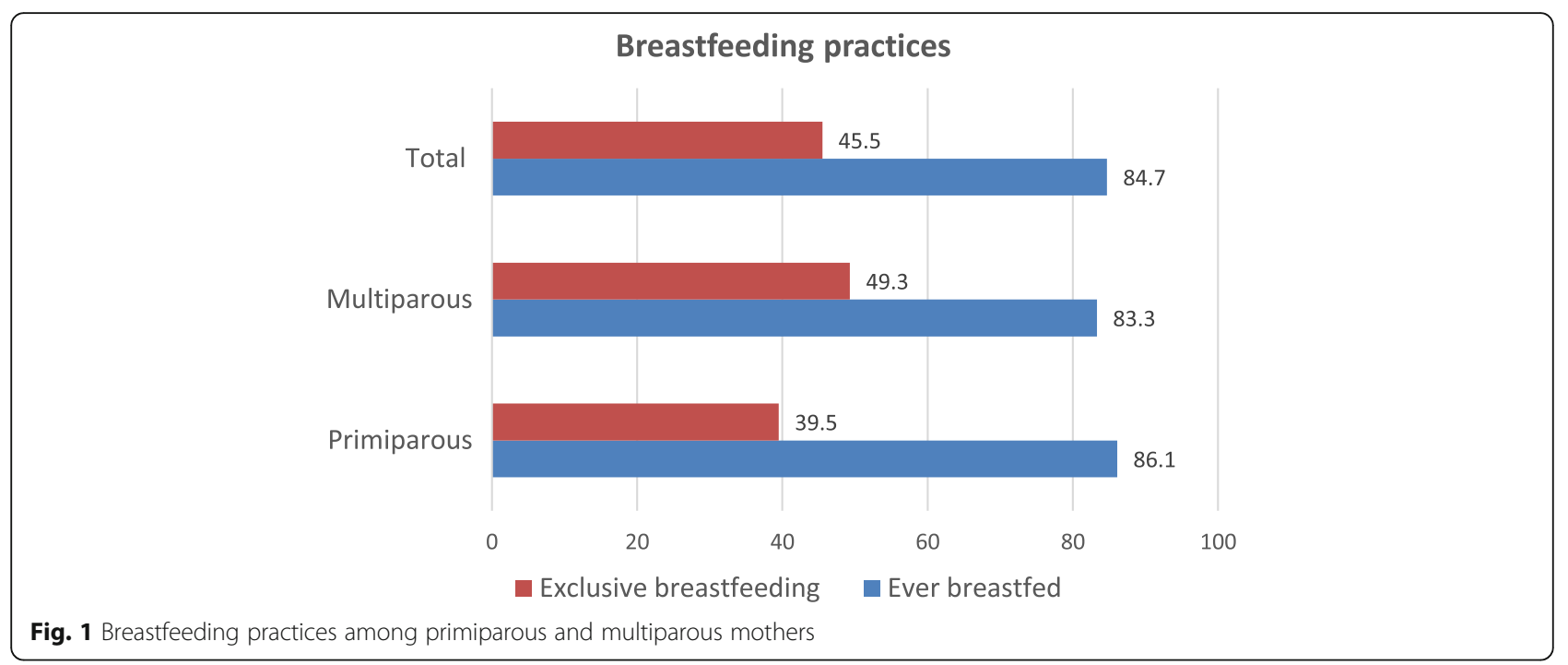

due to, not only food insecurity but also to poor accessibility to health services and infrastructure, such as roads and supply of water. The study area (Wajir County) is situated in an ASAL region. The NGOs working in partnership with the Ministry of Health are implementing services under the Community Health Strategy and thus making health and nutrition services more accessible to the population in such areas. The implementation of health and nutrition services under the Community Health Strategy is strong in areas where the NGOs are supporting the Ministry of Health in provision of services at the community level.

The current Kenya national exclusive breastfeeding rate is $61.4 \%$ as reported in the 2014 Kenya Demographic Health Survey [6]. The EBF rate in this survey was not only lower than the national rate but was also below the WHO recommended rate of 90\% [4] implying that concerted efforts are needed to improve the practice of EBF.
Overall, the mothers' knowledge on breastfeeding reported in our study was high. Primiparous mothers exhibited a higher knowledge score compared to the multiparous mothers although the difference was not statistically significant. The high knowledge among the mothers could be partly attributed to some of the government strategies to improve EBF rates, such as the Baby Friendly Hospital Initiative (BFHI), Baby Friendly Community Initiative (BFCI) and Mother-to-Mother Support groups. All are the key Ministry of Health and non-Governmental interventions promoting EBF at the national, health facility and community level. These strategies form the major focus of interventions aimed at improving infant and young child feeding practices as stipulated in the Kenya National Nutrition Action Plan [9]. Studies conducted in other areas in Kenya have also demonstrated high maternal knowledge on breastfeeding particularly on the duration of

Table 3 Maternal knowledge on breastfeeding

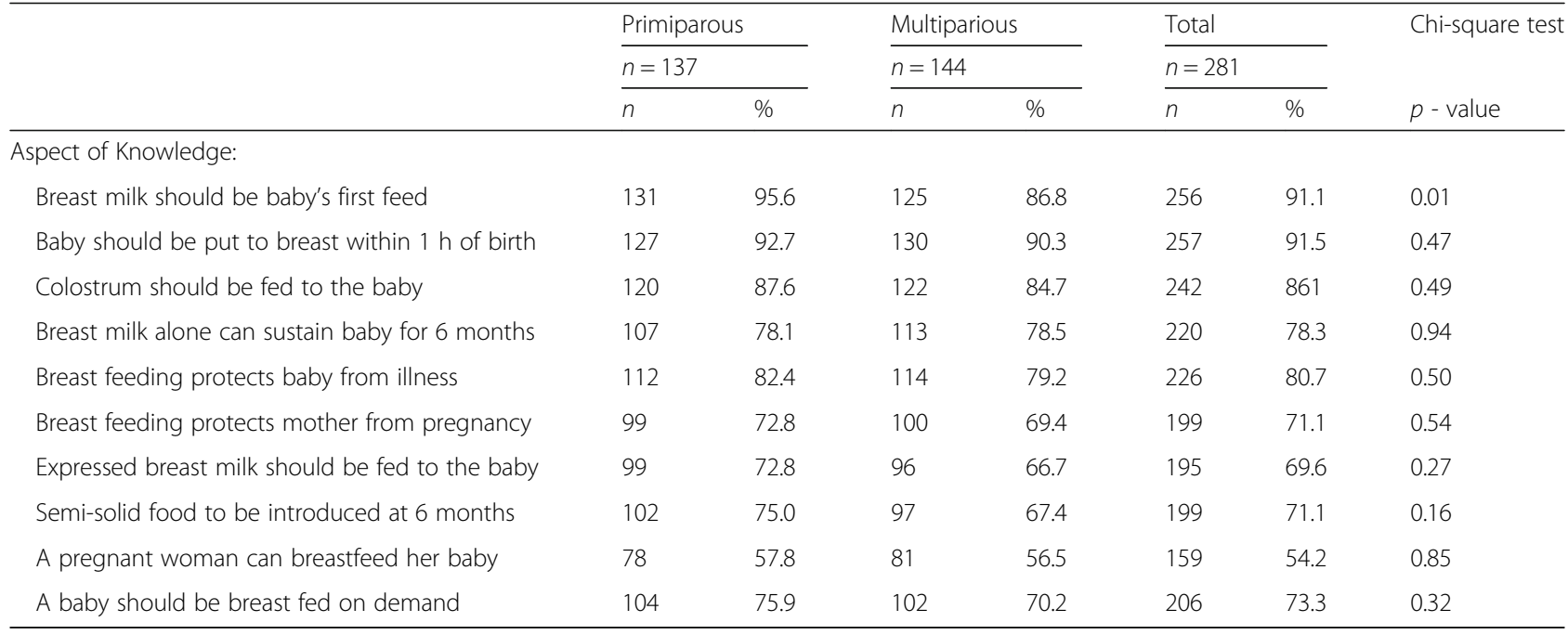


Table 4 Maternal attitudes towards breastfeeding

\begin{tabular}{|c|c|c|c|c|c|c|c|c|c|c|c|c|c|}
\hline \multirow{3}{*}{$\begin{array}{l}\text { Primiparous ( } n=137 \text { ) } \\
\text { Aspects of Attitude }\end{array}$} & \multicolumn{6}{|c|}{ Multiparous $(n=144)$} & \multicolumn{7}{|c|}{$x^{2}(p-$ value $)$} \\
\hline & \multicolumn{2}{|c|}{ Agree } & \multicolumn{2}{|c|}{ Disagree } & \multicolumn{2}{|c|}{ Neutral } & \multicolumn{2}{|c|}{ Agree } & \multicolumn{2}{|c|}{ Disagree } & \multicolumn{2}{|c|}{ Neutral } & \multirow[t]{2}{*}{$\overline{p-\text { value }}$} \\
\hline & $n$ & $\%$ & $n$ & $\%$ & $n$ & $\%$ & $n$ & $\%$ & $n$ & $\%$ & $n$ & $\%$ & \\
\hline Believe that EBF is beneficial to the child & 130 & 94.9 & 6 & 4.4 & 1 & 0.7 & 137 & 95.1 & 5 & 3.5 & 2 & 1.4 & 0.46 \\
\hline The age of the mother influences her ability to EBF & 107 & 78.1 & 20 & 14.6 & 10 & 7.3 & 104 & 72.2 & 21 & 14.6 & 19 & 13.2 & 0.28 \\
\hline A baby can survive without water & 89 & 65.0 & 41 & 29.9 & 7 & 5.1 & 92 & 63.9 & 42 & 29.2 & 10 & 6.9 & 0.52 \\
\hline $\begin{array}{l}\text { Husbands should be involved in decision making on } \\
\text { whether to EBF }\end{array}$ & 68 & 49.6 & 56 & 40.9 & 13 & 9.5 & 75 & 52.1 & 55 & 38.2 & 14 & 9.7 & 0.35 \\
\hline Animal milk is suitable for a new born baby & 74 & 54.0 & 51 & 37.2 & 12 & 8.8 & 61 & 42.4 & 63 & 43.8 & 20 & 13.9 & 0.06 \\
\hline Breast milk is inadequate for babies 2 months or older & 73 & 53.3 & 51 & 37.2 & 13 & 9.5 & 80 & 55.6 & 57 & 39.6 & 7 & 4.9 & 0.52 \\
\hline Formula feeding is better choice for working mothers & 38 & 27.7 & 87 & 63.5 & 12 & 8.8 & 56 & 38.9 & 77 & 53.5 & 11 & 7.6 & 0.03 \\
\hline Breastfed babies are healthier than fed babies & 120 & 87.6 & 12 & 8.8 & 5 & 3.6 & 114 & 79.2 & 19 & 13.2 & 11 & 7.6 & 0.06 \\
\hline Breast milk is more easily digested than formula & 118 & 86.1 & 13 & 9.5 & 6 & 4.4 & 110 & 76.4 & 21 & 14.6 & 13 & 9.0 & 0.04 \\
\hline Infant cannot survive without water besides breast milk & 56 & 40.9 & 73 & 53.3 & 8 & 5.8 & 56 & 38.9 & 75 & 52.1 & 13 & 9.0 & 0.50 \\
\hline $\begin{array}{l}\text { Number of times a mother has given birth will influence } \\
\text { her ability to EBF }\end{array}$ & 12 & 8.8 & 81 & 59.1 & 7 & 5.1 & 17 & 11.8 & 76 & 52.8 & 4 & 2.8 & 0.44 \\
\hline
\end{tabular}

exclusive breastfeeding [33]. The high level of knowledge on breastfeeding did not however necessarily translate into practice implying that factors other than knowledge influenced the choice of infant feeding in this community. The findings of many studies conducted in sub-Saharan Africa, Kenya included, have shown culture as having a major influence on infant feeding practices $[35,36]$. It is therefore possible that cultural beliefs related to infant feeding may have contributed to the choice of infant feeding in the study community. Cultural attitudes, beliefs and norms are important factors in the WHO's model of the determinants of infant and child feeding behavior [35] as they are known to affect breastfeeding practices. Other researchers have identified detrimental cultural beliefs (insufficient milk and "bad" colostrum) as a hindrance to the practice of exclusive breastfeeding [36].

Table 5 The association between maternal knowledge and attitude on breastfeeding with exclusive breastfeeding

\begin{tabular}{|c|c|c|c|}
\hline & \multicolumn{2}{|l|}{ EBF } & \multirow{4}{*}{$\begin{array}{l}\text { Fisher's exact } \\
\text { test ( } p \text { - value) }\end{array}$} \\
\hline & Yes & No & \\
\hline & $n=125$ & $n=156$ & \\
\hline & $n(\%)$ & $n(\%)$ & \\
\hline \multicolumn{4}{|c|}{ Knowledge score (out of 10): } \\
\hline Poor $\leq 3)$ & $3(2.4)$ & $8(5.1)$ & \\
\hline Medium (4-6) & $30(24.0)$ & $42(26.9)$ & \\
\hline High (> 7) & $90(73.6)$ & $106(67.9)$ & 0.42 \\
\hline \multicolumn{4}{|c|}{ Attitude score (out of 40): } \\
\hline Poor $\leq 20$ & $6(4.8)$ & $13(8.3)$ & \\
\hline Moderate 21-30 & $46(36.8)$ & $96(61.5)$ & \\
\hline Positive $>31$ & $73(58.4)$ & 47 (30.1) & 0.00 \\
\hline
\end{tabular}

The findings of our study show that maternal attitude towards exclusive breastfeeding was positive with no significant differences between the primiparous and multiparous mothers. The positive maternal attitude towards EBF can probably be explained by the fact that the Ministry of Health and Non-Governmental Organizations dealing with child health emphasise the improvement of breastfeeding practices through various strategies at both the health facility and community level, as well as through the media. Just like the reasons for the high knowledge among the mothers, it is probable the Ministry of Health Strategy and Interventions in improving IYCF practices and specifically EBF could have led to the positive attitudes among the mothers towards exclusive breastfeeding. In our study, those mothers with positive attitudes towards breastfeeding were more likely to exclusively breastfeed their infants.

One limitation of the study, was the use of the $24 \mathrm{~h}$ recall period data collection methodology for establishing EBF rate because it over estimates EBF since birth. Exclusive breastfeeding is defined as giving no other foods at all since birth and not just in the last $24 \mathrm{~h}$. This method overestimates the proportion of exclusively breastfed infants, as some infants who are given other liquids irregularly may not have received them the day before the survey. This is however, the method recommended by WHO and used in the DHS globally and therefore allows for comparison of our findings with that of other studies. Appropriate attention was given to ensure quality control of data by thorough training of the enumerators, and close supervision of all the study activities.

\section{Conclusions}

There were no significant differences in the knowledge, attitudes and practice of exclusive breastfeeding among 
primiparous and multiparous mothers. The findings of our study have demonstrated that parity did not influence the practice of exclusive breastfeeding of our study population. Interventions to promote exclusive breastfeeding should be tailored to the needs of each population. Positive attitudes towards breastfeeding were associated with exclusive breastfeeding but maternal knowledge was not. Efforts to promote exclusive breastfeeding should, in addition to improving maternal knowledge and attitudes, focus on the identification of factors that influence the practice and how they can be addressed in a participatory manner by all stakeholders in the community. The findings of our study will be useful particularly to those organizations that focus on behavior change communication interventions, to improve exclusive breastfeeding.

\section{Abbreviations}

ANC: Antenatal care; BFCl: Baby Friendly Community Initiative; BFHI: Baby Friendly Hospital Initiative; CHW: Community health workers; CWC: Child welfare clinic; DHS: Demographic health survey; EBF: Exclusive breastfeeding; FGD: Focus group discussion; IYCF: Infant and young child feeding; KAP: Knowledge, attitudes and practice; KDHS: Kenya demographic and health survey; KNBS: Kenya national bureau of statistics; MCH: Maternal child health; TBA: Traditional birth attendants

\section{Acknowledgements}

My special appreciation goes to my supervisors Dr. Sophie Ochola and Dr. Owino Victor Ochieng for their patience and unwavering willingness to provide direction and support throughout the study. My sincere appreciation to my family for their willingness to sacrifice their time and resources so that I could complete this master's degree.

\section{Funding}

The study was funded by the author and no external funding was solicited.

\section{Availability of data and materials}

The datasets during and/or analyzed during the current study available from the corresponding author on reasonable request.

\section{Authors' contributions}

MJM participated in the conceptualization and design of the study, performed data collection and led the data analysis and preparation of the manuscript. Dr. SO and Dr. VO participated in the conceptualization and design of the study, and participated in the data analysis, interpretation of data and preparation of the manuscript. All the authors read and approved the final manuscript.

\section{Ethics approval and consent to participate}

Authority to conduct the research was sought from the Graduate School of Kenyatta University. Ethical clearance to conduct the study was sought from the Ethical Review Committee of Kenyatta University (ref. number KU/R/ COMM/51/321) and permission to conduct the research from the National Commission for Science, Technology and Innovation (NACOSTI) - clearance reference number S. No. 3164. Informed written or thumb print consent was sought from the respondents who were selected to take part in the study. Mothers who were less than 18 years of age signed assent forms before participating in the study. Participants were assured of confidentiality. The names of the participants were included in the questionnaires only for reference during the interviews. All the participants were also assured that the information they gave would only be used for purposes of research and that findings would be communicated to them.

\section{Consent for publication}

Not applicable.

\section{Competing interests}

The authors declare that they have no competing interests.

\section{Publisher's Note}

Springer Nature remains neutral with regard to jurisdictional claims in published maps and institutional affiliations.

\section{Author details}

'Department of Food, Nutrition and Dietetics, Kenyatta University, P.O BOX 438433, Nairobi 00100, Kenya. ${ }^{2}$ Department of Human Nutrition and Dietetics, Technical University, P.O. BOX 52428, Nairobi 00200, Kenya.

Received: 18 January 2017 Accepted: 8 February 2018

Published online: 02 March 2018

\section{References}

1. WHO. Evidence for Nutrition Actions (eLENA) [Internet]. WHO. World Health Organization; 2017 Available from: http://www.who.int/elena/titles/ exclusive_breastfeeding/en/ (Accessed 4 Apr 2016).

2. WHO. Exclusive breastfeeding [Internet]. WHO. World Health Organization; 2017. Available from: http://www.who.int/nutrition/topics/exclusive_ breastfeeding/en/(Accessed 4 May 2016).

3. WHO. WHA Global Nutrition Targets 2025: Breastfeeding Policy Brief [Internet]. 2014. Available from: http://www.who.int/nutrition/topics/ globaltargets_breastfeeding_policybrief.pdf (Accessed 15 Jan 2016).

4. Victora CG, Bahl R, Barros AJD, França GVA, Horton S, Krasevec J, et al. Breastfeeding in the 21st century: epidemiology, mechanisms, and lifelong effect. Lancet. 2016;387:475-90. Available from: http:/www.sciencedirect. com/science/article/pii/S0140673615010247 (Accessed 17 Jan 2016

5. WHO. The data repository [Internet]. WHO. World Health Organization; 2016. Available from: http://www.who.int/gho/database/en/ (Accessed 10 March Apr 2016).

6. Kenya National Bureau of Statistics, ICF Macro. Kenya Demographic and Health Survey 2014. Calverton, Maryland: Kenya National Bureau of Statistics (KNBS); 2015.

7. Kenya National Bureau of Statistics, ICF Macro. Kenya Demographic and Health Survey 2008-09. Calverton, Maryland: Kenya National Bureau of Statistics (KNBS); 2010.

8. Islamic Relief, Ministry of Health. Knowledge, attitude and practices survey, Wajir County; 2014. 2014. Available from: http://www.nutritionhealth.or.ke/ wp-content/uploads/MIYCN\%20Assessments\%20Reports/ Wajir\%20MIYCN\%20KAP\%20Report\%20-\%20August\%202014.pdf Assessments Reports/Wajir MIYCN KAP Report - August 2014.pdf (Accessed 17 Dec 2014).

9. Republic of Kenya. National Nutrition Action plan 2012-2017 [Internet]. Minister for Public Health and Sanitation; 2012. Available from: https:// scalingupnutrition.org/wp-content/uploads/2013/10/Kenya-NationalNutrition-Action-Plan-2012-2017-final.pdf (Accessed 23 Sep 2014).

10. Mannel R, Martens P, Walker M. Core Curriculum for Lactation Consultant Practice. 3rd Edition. International Lactation Consultant Association; 2012. Available from: https://books.google.co.ke/books?hl=en\&lr=\&id= 8lrnu1fm2WUC\&oi=fnd\&pg=PR1\&dq=10.\%09Mannel, + R., + Martens,,+ P. + and +Walker, + S.+Core+Curriculum+for+Lactation:-International+Lactation +Consultant+Association+3rd+Edition.+2013.+\&ots=nv7JMFY3z1\&sig= aJ9afW2lOMDJ53HzK (Accessed 8 Aug 2014).

11. Sloan S, Sneddon H, Stewart M, Iwaniec D. Breast is best? Reasons why mothers decide to breastfeed or bottlefeed their babies and factors influencing the duration of breastfeeding. Child Care Pract. 2006;12:283-97. Taylor \& Francis Group. Available from: http://www.tandfonline.com/doi/ abs/10.1080/13575270600761743 (Accessed 20 July 2015)

12. Hackman NM, Schaefer EW, Beiler JS, Rose CM, Paul IM. Breastfeeding outcome comparison by parity. Breastfeed Med. 2015;10:156-62. Available from: http:// www.ncbi.nlm.nih.gov/pubmed/25549051(Accessed 25 Sep 2016)

13. Afiyanti $Y$, Afiyanti $Y$. Negotiating motherhood: the difficulties and challenges of rural first-time mothers in Parung, West Java. Makara J Heal Res. 2010;6:29-34. Available from: http://journal.ui.ac.id/index.php/health/ article/view/8 (Accessed 5 Feb 2014)

14. Minas AG, Ganga-Limando M, Quan L, Shafie M, Rani N, Ramli K. Socialcognitive predictors of exclusive breastfeeding among primiparous mothers in Addis Ababa, Ethiopia. Carpenter DO, editor. PLoS One. Blackwell Publishers; 2016;11:e0164128. Available from: http://dx.plos.org/10.1371/ journal.pone.0164128 (Accessed 25 Apr 2017).

15. Uusitalo L, Nyberg H, Pelkonen M, Sarlio-Lähteenkorva S, Hakulinen-Viitanen T, Virtanen S. Infant feeding in Finland 2010 [Internet]. Helsinki; 2012. 
Available from: http://www.julkari.fi/bitstream/handle/10024/90855/URN_ ISBN 978-952-245-59-7.pdf?sequence=1 (Accessed 23 June 2016).

16. Amin T, Hablas H, Al Qader AA. Determinants of initiation and exclusivity of breastfeeding in al Hassa, Saudi Arabia, vol. 6. New Rochelle: Breastfeed. Med. Mary Ann Liebert, Inc; 2011. p. 59-68. Available from: http://www. liebertonline.com/doi/abs/10.1089/bfm.2010.0018 (Accessed 24 Apr 2014)

17. Kaneko A, Kaneita Y, Yokoyama E, Miyake T, Harano S, Suzuki K, et al. Factors associated with exclusive breast-feeding in japan: for activities to support child-rearing with breast-feeding. J Epidemiol. 2006;16:57-63. Japan Epidemiological Association. Available from: http://joi.jlc.jst.go.jp/JST.JSTAGE/ jea/16.57?from=CrossRef (Accessed 3 Nov 2015)

18. Lande B, Andersen L, Baerug A, Trygg K, Lund-Larsen K, Veierød M, et al. Infant feeding practices and associated factors in the first six months of life: the Norwegian infant nutrition survey. Acta Paediatr. 2007;92:152-61. Blackwell Publishing Ltd. Available from: http://doi.wiley.com/10.1111/j.16512227.2003.tb00519.x. (Accessed 27 Oct 2016)

19. Agboado G, Michel E, Jackson E, Verma A. Factors associated with breastfeeding cessation in nursing mothers in a peer support programme in eastern Lancashire. BMC Pediatr. 2010;10:3. Available from: http://bmcpediatr. biomedcentral.com/articles/10.1186/1471-2431-10-3 (Accessed 3 Oct 2014)

20. Akter S, Rahman MM. Duration of breastfeeding and its correlates in Bangladesh. J Health Popul Nutr. 2010;28:595-601. BioMed Central. Available from: http://www.ncbi.nlm.nih.gov/pubmed/21261205 (Accessed 25 July 2015)

21. Dachew B, Bifftu B. Breastfeeding practice and associated factors among female nurses and midwives at North Gondar zone, Northwest Ethiopia: a cross-sectional institution based study. Int Breastfeed J. 2014;9:11. Available from: http://internationalbreastfeedingjournal.biomedcentral.com/articles/10. 1186/1746-4358-9-11 (Accessed 5 June 2015)

22. Khanal V, Sauer K, Zhao Y. Exclusive breastfeeding practices in relation to social and health determinants: a comparison of the 2006 and 2011 Nepal demographic and health surveys. BMC Public Health. 2013;13:958. Available from: http://www.ncbi.nlm.nih.gov/pubmed/24125095. (Accessed 25 Apr 2014)

23. Ekström A, Widström A-M, Nissen E. Duration of breastfeeding in Swedish primiparous and multiparous women. J Hum Lact. 2003:19:172-8. Available from: http://journals.sagepub.com/doi/10.1177/0890334403252537 (Accessed 2 Aug 2015)

24. Katzenellenbogen JM, Joubert G, Abdool KS. Epidemiology: a manual for South Africa. Am J Epidemiol Cape T. 1997;148:64-73. Oxford University Press Southern Africa

25. WHO. The World Health Organization's infant feeding recommendation. WHO. World Health Organization; 2015. Available from: http://www.who.int/nutrition/ topics/infantfeeding_recommendation/en/ (Accessed 31 Dec 2015).

26. WHO. Complementary feeding. 2015. Available from: http://www.who.int/ elena/titles/complementary_feeding/en/ (Accessed 25 July 2015).

27. Hackett KM, Mukta US, Jalal CSB, Sellen DW. Knowledge, attitudes and perceptions on infant and young child nutrition and feeding among adolescent girls and young mothers in rural Bangladesh. Matern Child Nutr. 2015;11:173-89. Available from: http:/doi.wiley.com/10.1111/mcn.12007 (Accessed 2 Jan 2016)

28. Israel G. Determining sample size. Gainesville: University of Florida; 1992. Available from: https://scholar.google.com/scholar?hl=en\&as_sdt=0\%2C5\&q= 28.\%091srael\%2C+G.D.+Determining+sample+size.+PEOD6.+University+of +Florida\%2C+IFAS+Extension.1992\&btnG= (Accessed 25 Jan 2016)

29. Tan K. Factors associated with exclusive breastfeeding among infants under six months of age in peninsular malaysia. Int Breastfeed J. 2011;6:2. Available from: http://internationalbreastfeedingjournal.biomedcentral.com/articles/10. 1186/1746-4358-6-2 (Accessed 26 Jan 2014)

30. Cronbach LJ, Shavelson RJ. My current thoughts on coefficient alpha and successor procedures. Educ Psychol Meas. 2004;64:391-418.

31. Ochola SA. Evaluation of two counseling strategies improving exclusive breastfeeding among HIV-negative mothers in Kibera slum, Nairobi, Kenya : a randomized controlled trial. Stellenbosch: Stellenbosch University; 2008. Available from: http://scholar.sun.ac.za/handle/10019.1/1460 (Accessed 23 Oct 2014)

32. Nyanga N, Musita C, Otieno A, Kaseje D. Factors influencing knowledge and practice of exclusive breastfeeding in Nyando district, Kenya. African J Food Agric Nutr Dev. 2013;16(10):1732-40. Available from: https://www.ajol.info/ index.php/ajfand/article/view/82781 (Accessed 18 Sep 2015)

33. Kimani-Murage E, Madise NJ, Fotso J-C, Kyobutungi C, Mutua MK, Gitau TM, et al. Patterns and determinants of breastfeeding and complementary feeding practices in urban informal settlements, Nairobi Kenya. BMC Public Health. 2011;1:396. Available from: http://www.biomedcentral.com/14712458/11/396 (Accessed 10 Jul 2015)
34. Ochola SA, Labadarios D, Nduati RW. Impact of counselling on exclusive breast-feeding practices in a poor urban setting in Kenya: a randomized controlled trial. Public Health Nutr. 2013;16:1732-40. Available from: https:// pdfs.semanticscholar.org/9af8/eb3955811a1e53c556f44b52e127582c963b. pdf (accessed 10 Jan 2016)

35. Wanjohi M, Griffiths P, Wekesah F, Muriuki P, Muhia N, Musoke RN, et al. Sociocultural factors influencing breastfeeding practices in two slums in Nairobi, Kenya. Int Breastfeed J. 2016;12:5. Available from: https://www.ncbi. nlm.nih.gov/pmc/articles/PMC5225512/. Accessed 16 Jan 2016.

36. Ogada IA. Effectiveness of couple counselling versus maternal counselling in promoting exclusive breast feeding: a randomised controlled trial in Nyando District, Kenya [Internet]. Kenyatta University; 2014. Available from: http://ir-library.ku.ac.ke/handle/123456789/11910 of couple counselling versus maternal counselling in promoting exclusive breast feeding a randomised controlled trial in Nyando District, Kenya (Accessed 10 Jan 2015).

\section{Submit your next manuscript to BioMed Central and we will help you at every step:}

- We accept pre-submission inquiries

- Our selector tool helps you to find the most relevant journal

- We provide round the clock customer support

- Convenient online submission

- Thorough peer review

- Inclusion in PubMed and all major indexing services

- Maximum visibility for your research

Submit your manuscript at www.biomedcentral.com/submit
C Biomed Central 